\title{
Management of multidrug-resistant enterococcal infections
}

\author{
C. A. Arias ${ }^{1,2,3}$, G. A. Contreras ${ }^{3,4}$, and B. E. Murray ${ }^{1,5}$ \\ ${ }^{1}$ Department of Internal Medicine, Division of Infectious Diseases and Center for the Study of \\ Emerging and Reemerging Pathogens, University of Texas Medical School at Houston, Houston, \\ TX, USA \\ 2 Center for the Study of Emerging and Reemerging Pathogens, Laboratory for Antimicrobial \\ Research, University of Texas Medical School at Houston, Houston, TX, USA \\ ${ }^{3}$ Molecular Genetics and Antimicrobial Resistance Unit, Universidad El Bosque, Bogotá, \\ Colombia \\ ${ }^{4}$ Division of Pediatric Infectious Diseases, Department of Pediatrics, University of Texas Medical \\ School at Houston, Houston, TX, USA \\ ${ }^{5}$ Department of Microbiology and Molecular Genetics, University of Texas Medical School at \\ Houston, Houston, TX, USA
}

\section{Abstract}

Enterococci are organisms with a remarkable ability to adapt to the environment and acquire antibiotic resistance determinants. The evolution of antimicrobial resistance in these organisms poses enormous challenges for clinicians when faced with patients affected with severe infections. The increased prevalence and dissemination of multidrug-resistant Enterococcus faecium worldwide has resulted in a major decrease in therapeutic options because the majority of $E$. faecium isolates are now resistant to ampicillin and vancomycin, and exhibit high-level resistance to aminoglycosides, which are three of the traditionally most useful anti-enterococcal antibiotics. Newer antibiotics such as linezolid, daptomycin and tigecycline have good in vitro activity against enterococcal isolates, although their clinical use may be limited in certain clinical scenarios as a result of reduced rates of success, possible underdosing for enterococci and low serum levels, respectively, and also by the emergence of resistance. The experimental agent oritavancin may offer some hope for the treatment of vancomycin-resistant enterococci but clinical data are still lacking. Thus, optimal therapies for the treatment of multidrug-resistant enterococcal infections continue to be based on empirical observations and extrapolations from in vitro and animal data. Clinical studies evaluating new strategies, including combination therapies, to treat severe vancomycin-resistant $E$. faecium infections are urgently needed.

\section{Keywords}

Antibiotics; enterococci; resistance; review; vancomycin

\section{Introduction}

Enterococci are common causes of nosocomial infections and are ranked second (after staphylococci) as aetiological agents of hospital-associated infections in US hospitals, with

(C2010 The Authors Journal Compilation (2010 European Society of Clinical Microbiology and Infectious Diseases Corresponding author and reprint requests: B. E. Murray, 6431 Fannin Street MSB 2.112, Houston, TX 77030, USA barbara.e.murray@uth.tmc.edu. 
Enterococcus faecalis and Enterococcus faecium currently isolated in an approximately 1.5:1 ratio [1]. In Europe, the prevalence of vancomycin resistance in enterococci appears to be increasing, with important regional differences (highest in Greece, UK and Portugal) $[2,3]$. The ability of enterococci to colonize the gastrointestinal (GI) tract of hospitalized humans for long periods is a crucial factor that influences the development of drug resistance. Inside the GI tract, enterococci serve as a reservoir for cycles of transmission and spread of antibiotic resistance determinants [4]. The emergence of resistance to the most common anti-enterococcal antibiotics has made the treatment of these infections a real challenge for clinicians. We review the current and possible future therapeutic options for the management of infections caused by multidrug-resistant (MDR) enterococci.

\section{Therapeutic Choices and Resistance}

\section{$\beta$-lactams and synergism with aminoglycosides}

Enterococci are often tolerant to the activity of penicillin and other $\beta$-lactams; this property differentiates enterococci from most streptococci which, in general, are also susceptible to much lower concentrations of $\beta$ lactams. Although rare, resistance to $\beta$-lactam antibiotics in $E$. faecalis is usually mediated by the production of a $\beta$ lactamase enzyme $[5,6]$. Non- $\beta$ lactamase-mediated resistance to ampicillin and imipenem has also been reported in $E$. faecalis and appears to be associated with mutations of the $p b p 4$ gene [7]. Conversely, resistance to $\beta$ lactams in most clinical isolates of $E$. faecium is associated with mutations or overproduction of PBP5, with ampicillin MICs of $>256 \mathrm{mg} / \mathrm{L}$ in some strains [8]. The emergence of $\beta$ lactam resistance precludes the use of these compounds for the treatment of severe enterococcal infections with two notable exceptions: (i) infections caused by $\beta$ lactamase-producing $E$. faecalis may respond to a $\beta$-lactam/ $\beta$ lactamase inhibitor combination (e.g. ampicillin-sulbactam) plus an aminoglycoside when treating endocarditis $[9,10]$ and (ii) strains of $E$. faecium with MICs of ampicillin of $564 \mathrm{mg} / \mathrm{L}$ may respond to high-dose ampicillin therapy (18-30 g per day plus one of the recommended aminoglycosides) because sufficient plasma concentrations (>150 mg/L) can be achieved with the high-dose regimen (Fig. 1) [8].

In spite of the good in vitro inhibitory activity of ampicillin and penicillin against most $E$. faecalis, previous in vitro and in vivo studies have shown that $\beta$ lactam monotherapy is associated with a poor outcome in patients with endovascular infections. These infections usually require bactericidal therapy that, for many strains, is not achieved with the use of ampicillin or penicillin alone as a result of the tolerance (lack of killing) of enterococci to these compounds. Moreover, certain enterococcal strains are killed only at a specific concentration of the $\beta$-lactam, above which the killing effect decreases (designated the Eagle effect [11]), making the success of $\beta$-lactam monotherapy unpredictable for severe enterococcal infections. With rare exceptions, synergistic and bactericidal therapy can be reliably achieved with the addition of an aminoglycoside to the $\beta$-lactam (or other cell wall agent such as vancomycin), as long as the organism does not exhibit high-level resistance (HLR) to the aminoglycoside, making this combination the standard of care for severe enterococcal infections [12]. Gentamicin and streptomycin are the recommended aminoglycosides for synergistic therapy in combination with a cell wall agent and the use of other compounds of this family is not recommended because of the frequent presence of the aminoglycoside 6 -acetyltransferase (an intrinsic feature of $E$. faecium, precluding the use of tobramycin, kanamycin, netilmicin and sisomicin) and the aph-(3')-IIIa gene that confers HLR to kanamycin and abolishes synergism with amikacin. Although enterococci are not susceptible to gentamicin and streptomycin at levels used for other organisms (considered to be a result of a decrease in the permeability of the cell wall), the addition of an agent that blocks peptidoglycan synthesis markedly increases the uptake of these antibiotics [13-16]. Nonetheless, in recent years, the acquisition of ribosomal mutations and/or aminoglycoside 
modifying enzymes that confer HLR to streptomycin or gentamicin continue to increase worldwide (although independent mechanisms, both can occur in the same strain). HLR to streptomycin and gentamicin is defined as growth at concentrations of 2000 and $500 \mathrm{mg} / \mathrm{L}$, respectively, thereby eliminating the synergistic bactericidal effect of the combination of the cell wall agent and the aminoglycoside [12-15]. The European Committee on Antimicrobial Susceptibility Testing (EUCAST) has defined HLR to gentamicin as MIC $>128 \mathrm{mg} / \mathrm{L}$ (EUCAST website: http://www.eucast.org/clinical_breakpoints/ for relevant clinical breakpoints). The bifunctional enzyme AAC (6')-Ie-APH(2")-Ia (i.e. the most commonly found enzyme) confers resistance to all available aminoglycosides, except streptomycin. Other enzymes found in enterococci include ANT(6)-Ia and APH(2")-Ic, which confer resistance to streptomycin and gentamicin, respectively [13].

In addition to the widespread dissemination of genes encoding aminoglycoside-modifying enzymes (see above), the use of aminoglycosides is limited in critically ill patients because of their nephrotoxic potential. The combination of ceftriaxone (or cefotaxime) and ampicillin has been recently tested as an alternative. The rationale for the use of this combination is based on observations that complementary saturation and inhibition of $E$. faecalis PBPs by ceftriaxone and ampicillin can result in a synergistic effect $[17,18]$. Clinical support for this concept has been documented in a nonrandomized trial that involved 13 hospitals in Spain [19]; of note, this synergistic effect was not observed with $E$. faecium isolates. Additionally, the success of ampicillin, imipenem plus vancomycin for the management of $E$. faecalis endocarditis with HLR to aminoglycosides has been reported. In experimental endocarditis caused by vancomycin-resistant $E$. faecium, the combination of ampicillin and imipenem produced a statistically significant decrease in bacterial counts from vegetations (5- $\log _{10}$ ) compared to the most active single agent in an animal model of endocarditis $[20,21]$.

\section{Glycopeptides and lipoglycopeptides}

The isolation of vancomycin-resistant enterococci (VRE) has steadily increased worldwide subsequent to 1986. A recent study from the CDC indicates that, among 983 E. faecium isolates analyzed (2006-2007), 80\% were resistant to vancomycin; conversely, just $6.9 \%$ of $E$. faecalis isolates were vancomycin-resistant $(n=1542)$ [1]. In Europe, the emergence of VRE was initially correlated with the use of the glycopeptide avoparcin, which was used as a growth promoter in animal husbandry. However, even after the ban of avoparcin, the European continent has continued to experience an important increase in the isolation of $\operatorname{VRE}(E$. faecium) from hospitals, indicating that other factors are promoting the dissemination of VRE in Europe. The increased isolation of vancomycin-resistant $E$. faecium in hospitals worldwide has been attributed to the emergence of a specific genetic lineage designated clonal cluster 17 [22]. Vancomycin resistance continues to evolve in enterococci and newer phenotypes have been described. Because of the increased presence of gene clusters conferring resistance to glycopeptides in E. faecium, vancomycin has become almost obsolete for the treatment of $E$. faecium infections (at least in the USA).

Telavancin is a derivative of vancomycin and also binds to the ${ }_{\mathrm{D}}$-alanine- $\mathrm{D}$-alanine terminus of peptidoglycan precursors; unlike vancomycin, telavancin also produces disruption of the bacterial membrane potential leading to increased cell permeability, which is thought to contribute to the mechanism of bacterial killing $[23,24]$. Telavancin was recently approved by the Food and Drug Administration (FDA) for the treatment of complicated skin and skin structure infections (including those caused by vancomycin-susceptible E. faecalis), but is not likely to be useful for the treatment of VRE infections because effective killing will not be attained at the doses recommended [12,25]. 
Oritavancin is a glycopeptide semisynthetic derivative of chloroeremomycin with the interesting property that it retains activity against VRE. In a clinical trial evaluating the efficacy of oritavancin for skin and soft tissue infections (mostly caused by staphylococci and streptococci), this antibiotic was comparable to vancomycin (approximately 78\%) [26,27]. Recent data using solid-state nuclear magnetic resonance imaging suggest that the increased activity of oritavancin against VRE isolates (E. faecium) is a result of the presence of binding sites other than to the ${ }_{\mathrm{D}}$-Ala-d-Ala terminus of peptidoglycan precursors [28]. Oritavancin also appears to disrupt membrane potential and permeability [29]. In experimental endocarditis (rabbit) caused by strains of vancomycin-resistant $E$. faecalis (VanA or VanB phenotype), an intramuscular regimen of $20 \mathrm{mg} / \mathrm{kg}$ produced a significant reduction in the bacterial counts of vegetations compared to controls. Nonetheless, mutants with increased oritavancin MICs were selected in the VanA-type strains (approximately $10^{-7}$ ), although the addition of gentamicin prevented the selection of mutants and provided a synergistic effect [30,31].

\section{Daptomycin}

Daptomycin is a lipopeptide antibiotic [32] that has FDA- and European Medicines Agency (EMEA)-approved indications for the treatment of complicated skin and soft tissue infections caused by susceptible Gram-positive organisms (they do not include VRE, and EUCAST daptomycin breakpoints for enterococci have not been set) and bacteraemia caused by Staphylococcus aureus. The mechanism of action involves the interaction of the antibiotic with the cytoplasmic membrane via the calcium-dependent insertion of its hydrophobic moiety leading to alteration of membrane potential and permeability [33]. Daptomycin has concentration-dependent bactericidal activity against enterococci in in vitro models and the pharmacodynamic parameters that correlate best with antimicrobial activity appear to be the area under the curve/MIC and peak concentration/MIC ratios [34,35]; in vitro synergism with rifampin (against $E$. faecium), fosfomycin (against $E$. faecalis) and gentamicin (against $E$. faecalis) has been described [36-38].

Emergence of daptomycin-resistant strains with treatment failures has been documented with standard daptomycin dose monotherapy $(6 \mathrm{mg} / \mathrm{kg})$ and it has been postulated that the use of higher doses (up to $12 \mathrm{mg} / \mathrm{kg}$ ) is likely to be more effective against enterococcal isolates, which, in general, exhibit higher MICs than staphylococci or streptococci. Additionally, the combination of daptomycin with other agents may offer certain clinical advantages in the setting of enterococcal endocarditis [36,37]. Combinations of high-dose daptomycin $(8 \mathrm{mg} / \mathrm{kg})$ plus ampicillin plus gentamicin and daptomycin plus gentamicin plus rifampin have been reported to have successfully achieved cure in two patients with vancomycin-resistant $E$. faecium endocarditis [39,40]. More recently, two case reports have documented the successful combination of high-dose daptomycin with tigecycline in the treatment of endocarditis [41,42]. Furthermore, in a case of meningitis caused by MDR $E$. faecium, clinical cure with intravenous daptomycin and tigecycline plus intrathecal daptomycin was achieved in a paediatric patient [43]. In conclusion, higher doses of daptomycin should be considered as an alternative for the treatment of endovascular enterococcal infections and the addition of another active agent may have a clinical benefit, perhaps by preventing the emergence of resistant mutants, and should be carefully weighed in the face of severe endovascular infections (Fig. 1).

\section{Linezolid}

Linezolid is an oxazolidinone antibiotic that inhibits bacterial ribosomal protein synthesis [44]. Clinically relevant linezolid resistance in enterococci is mostly mediated by mutations in domain $\mathrm{V}$ of the $23 \mathrm{~S}$ rRNA, which appear to alter the interaction of the antibiotic with its target $[45,46]$. Even though linezolid has an FDA approval for some VRE infections (Table 
1) and is recommended by the American Heart Association [47] for the treatment of endocarditis as a result of multidrug-resistant enterococci, the use of linezolid in severe enterococcal infections is a matter of controversy, mainly because of the lack of a bactericidal effect and a paucity of prospective randomized clinical trials. In 2003, an openlabel, noncomparative and nonrandomized study that evaluated the efficacy of linezolid for Gram-positive infections found that the clinical cure and microbiologic eradication rates for vancomycin-resistant E. faecium bacteraemia were $78 \%$ and $85 \%$, respectively [46]; in the case of bacteraemia as a result of endocarditis, the percentages of clinical and microbiological success were lower (76\% and 63\%, respectively). In this study, however, a significant number of the patients were lost to follow up and only a small sample size was available for evaluation; thus, the actual efficacy of linezolid may have been overestimated [46]. A small meta-analysis performed to assess the available data related with the efficacy of linezolid in the treatment of endocarditis indicated that seven out of eight cases of enterococcal endocarditis were cured or achieved resolution of the infectious episode. The previous use of an unsuccessful therapy and/or allergy to other antibiotics were the principal reasons for the use of linezolid therapy in this study [48]. A shortcoming of this study is related to publication bias because positive results are much more likely to be reported than treatment failures (although linezolid failures in the treatment of enterococcal endocarditis have also been well documented). In view of the paucity of solid clinical evidence, and, until further data are available, we suggest that linezolid be used with caution in the treatment of VRE endocarditis, and only when resistance, side effects or allergy prevent the use of combinations of $\beta$-lactams and aminoglycosides, high-dose daptomycin plus other active agents or quinupristin-dalfopristin- based regimens (Fig. 1) [49-51]. Nonetheless, as a result of the good pharmacokinetic profile of linezolid in the central nervous system (CNS), this antibiotic may be a good first choice for the treatment of enterococcal meningitis or related CNS infections [52,53], especially when caused by vancomycin-resistant $E$. faecium.

\section{Quinupristin-dalfopristin}

Quinupristin-dalfopristin (Q/D) is a streptogramin antibiotic only active against $E$. faecium [54]; most $E$. faecalis are resistant as a result of the presence of a gene designated Isa, whose function has not been established [55]. Q/D inhibits protein synthesis by interacting with the $50 \mathrm{~S}$ ribosomal subunit $[56,57]$ and several mechanisms of resistance have been documented in enterococci $[58,59]$. The efficacy and safety of Q/D was evaluated in a prospective, multicentre noncomparative study for the treatment of vancomycin-resistant $E$. faecium infections for which no appropriate alternative antibiotic therapy was available. An overall clinical response was observed in $65.6 \%$ of patients and varied according to enrollment indication (e.g. $80 \%$ for urinary tract infections and $72 \%$ for bacteraemia of unknown origin). Arthralgia and myalgia were the most common adverse events, which, in some cases, led to the discontinuation of therapy [60]. Q/D has also been used as part of a combination regimen in the treatment of $E$. faecium endocarditis. In one patient with infective endocarditis, sterilization of the blood was only obtained after the addition of doxycycline and rifampin to Q/D [61]. Microbiological eradication in E. faecium endocarditis in a cancer patient was also achieved after the use of a regimen that included high-dose ampicillin (32 g/day) and Q/D [61,62]. The use of Q/D as part of a combination regimen was also shown to be effective in a rabbit model of endocarditis where the combination of $\mathrm{Q} / \mathrm{D}$ with imipenem or levofloxacin caused a greater decrease in CFU isolated from vegetations than Q/D alone [62]. Although Q/D has an FDA indication for treatment of vancomycin-resistant E. faecium (Table 1), we suggest that it may be preferable to use $\mathrm{Q} / \mathrm{D}$ as part of a combination regimen (i.e. with doxycycline, gentamicin, rifampin, ampicillin, imipenem or levofloxacin), when possible, although clinical data are still lacking and the use of this antibiotic is often hampered by side effects that may lead to the 
discontinuation of therapy. Of note, the American Heart Association lists Q/D as an option for the treatment of MDR E. faecium endocarditis (Fig. 1).

\section{Tigecycline}

Tigecycline is a broad-spectrum antibiotic derived from minocycline [63] which is FDA and EMEA approved for skin and soft tissue infections, including those with vancomycinsusceptible $E$. faecalis. Tigecycline inhibits protein synthesis upon interaction with the bacterial 30S ribosomal subunit [64] and only one case of tigecycline-resistant $E$. faecalis has been documented, although the exact mechanism of resistance has not yet been elucidated [65]. In the management of soft tissue infections (including those with vancomycin-susceptible $E$. faecalis), tigecycline showed a microbiological eradication rate of $87.5 \%$, similar to vancomycin plus aztreonam (91.7\%) [66]. In a trial evaluating the treatment of complicated abdominal infections, tigecycline and imipenemcilastatin exhibited similar rates of microbiological eradication for vancomycin-susceptible E. faecalis $(78.8 \%$ and $74.5 \%$, respectively) [67]. Some in vitro models suggest that synergism of tigecycline combined with vancomycin, gentamicin, doxycycline (in a doxycycline-resistant strain of $E$. faecium) or rifampin can be achieved for certain strains of $E$. faecalis and $E$. faecium compared to tigecycline alone [68]. Recently, successful therapy of endocarditis with the combination of tigecycline plus daptomycin has been documented in two cases of enterococcal endocarditis $[67,68]$. A serious drawback of the use of tigecycline monotherapy for the treatment of bacteraemia and endocarditis is the low serum levels obtained with this antibiotic $[68,69]$; thus, the use of this compound as monotherapy for severe enterococal infections is discouraged. Tigecycline may play a role in combination therapies with bactericidal agents (Fig. 1); however, prospective, clinical data to support this use are still lacking.

\section{Other antibiotics with anti-enterococcal activity}

Nitrofurantoin and fosfomycin tromethamine are useful alternatives for the management of lower uncomplicated urinary tract infections as a result of enterococci [71] (fosfomycin is FDA approved for urinary tract infections caused by vancomycin-susceptible E. faecalis). Similarly, chloramphenicol has been used for the treatment of VRE infections; chloramphenicol was used in 51 patients with VRE bloodstream infections, of whom 61\% had a favourable clinical response and 79\% exhibited microbiological eradication with no major side effects $[72,73]$. Also, the tetracycline group of antibiotics has been used as part of combination therapies in the treatment of severe MDR enterococcal infections. As mentioned above, the combination of $\mathrm{Q} / \mathrm{D}$ plus doxycycline and rifampin was successfully used to treat a patient with endocarditis as a result of E. faecium [74]; similarly, chloramphenicol plus minocycline was used in patient with prosthetic valve endocarditis caused by MDR E. faecium as salvage therapy [75]. In an in vitro dynamic model that simulated antibiotic concentrations and attempted to characterize the effect of antibiotic concentrations on the development of resistance, doxycycline was found to prevent the development of linezolid resistance at the mutant selection window concentrations [76]. The fluoroquinolones have also been used in the treatment of some enterococcal infections; for example, chronic enterococcal prostatitis with relapsing bacteraemia as a result of $E$. faecalis was successfully treated with a prolonged course of moxifloxacin [77]. Similar to the tetracyclines, fluoroquinolones have also been used as part of combination therapies in endocarditis [78]. The combination of ampicillin plus ciprofloxacin was tested in an experimental model of rabbit endocarditis with $E$. faecalis; the regimen caused a significant decrease in bacterial counts compared to each compound alone, although it was less effective than the combination of $\beta$-lactams and aminoglycosides [79]. Nonetheless, the lack of clinical experience and the increased rates of resistance to some of these compounds (e.g. fluoroquinolones) usually preclude the use of these antibiotics for MDR enterococci, 
particularly as monotherapy. Finally, ceftobiprole and ceftaro-line are new-generation cephalosporins with potential activity against vancomycin-resistant $E$. faecalis [80-82] (Table 1), although clinical data are still lacking.

\section{Acknowledgments}

C.A.A. is supported by NIH Pathway to Independence award K99/R00 AI72961 from the National Institute of Allergy and Infectious Diseases (NIAID). B.E.M. has grant support from NIH (grant R01 AI067861 and R37 AI47923 from the NIAID). C.A.A. has received lecture fees Novartis, Pfizer and Merck and grant support from Pfizer. B.E.M. has had grant support from Johnson and Johnson, Astellas and Intercell and has served as a consultant for Astellas, Theravance, Cubist, Targanta, Johnson and Johnson and Pfizer.

\section{References}

1. Hidron AI, Edwards JR, Patel J, Horan TC, Sievert DM, Pollock DA, et al. NHSN annual update: antimicrobial-resistant pathogens associated with healthcare-associated infections: annual summary of data reported to the National Healthcare Safety Network at the Centers for Disease Control and Prevention, 2006-2007. Infect Control Hosp Epidemiol. 2008; 29:996-1011. See Erratum 2009 Jan; 30(1):107. [PubMed: 18947320]

2. Brown DF, Hope R, Livermore DM, et al. Non-susceptibility trends among enterococci and nonpneumococcal streptococci from bacteraemias in the UK and Ireland, 2001-06. J Antimicrob Chemother. 2008; 62(suppl 2):ii75-ii85. [PubMed: 18819982]

3. Werner G, Coque TM, Hammerum AM, et al. Emergence and spread of vancomycin resistance among enterococci in Europe. Euro Surveill. 2008; 20:13.

4. Patel R. Clinical impact of vancomycin-resistant enterococci. J Antimicrob Chemother. 2003; 51(suppl 3):iii13-iii21. [PubMed: 12801938]

5. Murray BE. Beta-lactamase-producing enterococci. Antimicrob Agents Chemother. 1992; 36:23552359. [PubMed: 1489177]

6. Murray BE, Mederski-Samaroj B. Transferable beta-lactamase. A new mechanism for in vitro penicillin resistance in Streptococcus faecalis. J Clin Invest. 1983; 72:1168-1171. [PubMed: 6411768]

7. Ono S, Muratani T, Matsumoto T. Mechanisms of resistance to imipenem and ampicillin in Enterococcus faecalis. Antimicrob Agents Chemother. 2005; 49:2954-2958. [PubMed: 15980374]

8. Murray BE. Vancomycin-resistant enterococcal infections. N Engl J Med. 2000; 10:710-721. [PubMed: 10706902]

9. Rice LB, Calderwood SB, Eliopoulos GM, Farber BF, Karchmer AW. Enterococcal endocarditis: a comparison of prosthetic and native valve disease. Rev Infect Dis. 1991; 13:1-7. [PubMed: 2017607]

10. Wells VD, Wong ES, Murray BE, Coudron PE, Williams DS, Markowitz SM. Infections due to beta-lactamase-producing, high-level gentamicin-resistant Enterococcus faecalis. Ann Intern Med. 1992; 4:285-292. [PubMed: 1733382]

11. Eagle H. Further observations on the zone phenomenon in the bactericidal action of penicillin. J Bacteriol. 1951; 62:663-668. [PubMed: 14897844]

12. Arias CA, Murray BE. Emergence and management of drug-resistant enterococcal infections. Expert Rev Anti Infect Ther. 2008; 6:637-655. [PubMed: 18847403]

13. Chow JW. Aminoglycoside resistance in enterococci. Clin Infect Dis. 2000; 31:586-589. [PubMed: 10987725]

14. Moellering RC Jr, Weinberg AN. Studies on antibiotic syngerism against enterococci. II. Effect of various antibiotics on the uptake of 14 C-labeled streptomycin by enterococci. J Clin Invest. 1971; 50:2580-2584. [PubMed: 5001959]

15. Zimmermann RA, Moellering RC Jr, Weinberg AN. Mechanism of resistance to antibiotic synergism in enterococci. J Bacteriol. 1971; 105:873-879. [PubMed: 4994038]

16. Mederski-Samoraj BD, Murray BE. High-level resistance to gentamicin in clinical isolates of enterococci. J Infect Dis. 1983; 147:751-757. [PubMed: 6404994] 
17. Kariyama R, Kumon $\mathrm{H}$, Chow L, et al. In-vitro activity of the combination of ampicillin and arbekacin against high-level gentamicin-resistant enterococci. J Antimicrob Chemother. 1998; 42:836-838. [PubMed: 10052913]

18. Mainardi JL, Gutmann L, Acar JF, Goldstein FW. Synergistic effect of amoxicillin and cefotaxime against Enterococcus faecalis. Antimicrob Agents Chemother. 1995; 39:1984-1987. [PubMed: 8540703]

19. Gavalda J, Len O, Miro JM, et al. Brief communication: treatment of Enterococcus faecalis endocarditis with ampicillin plus ceftriaxone. Ann Intern Med. 2007; 8:574-579. [PubMed: 17438316]

20. Antony SJ, Ladner J, Stratton CW, Raudales F, Dummer SJ. High-level aminoglycoside-resistant enterococcus causing endocarditis successfully treated with a combination of ampicillin, imipenem and vancomycin. Scand J Infect Dis. 1997; 29:628-630. [PubMed: 9571747]

21. Brandt CM, Rouse MS, Laue NW, Stratton CW, Wilson WR, Steckelberg JM. Effective treatment of multidrug-resistant enterococcal experimental endocarditis with combinations of cell wallactive agents. J Infect Dis. 1996; 173:909-913. [PubMed: 8603970]

22. Werner G, Coque TM, Hammerum AM, Hope R, Hryniewicz W, Johnson A, et al. Emergence and spread of vancomycin resistance among enterococci in Europe. Euro Surveill. 2008; 13:19046. [PubMed: 19021959]

23. Higgins DL, Chang R, Debabov DV, et al. Telavancin, a multifunctional lipoglycopeptide, disrupts both cell wall synthesis and cell membrane integrity in methicillin-resistant Staphylococcus aureus. Antimicrob Agents Chemother. 2005; 49:1127-1134. [PubMed: 15728913]

24. Leonard SN, Rybak MJ. Telavancin: an antimicrobial with a multifunctional mechanism of action for the treatment of serious gram-positive infections. Pharmacotherapy. 2008; 28:458-468. [PubMed: 18363530]

25. Saravolatz LD, Stein GE, Johnson LB. Telavancin: a novel lipoglycopeptide. Clin Infect Dis. 2009; 49:1908-1914. [PubMed: 19911938]

26. Cooper RD, Snyder NJ, Zweifel MJ, et al. Reductive alkylation of glycopeptide antibiotics: synthesis and antibacterial activity. J Antibiot (Tokyo). 1996; 49:575-581. [PubMed: 8698642]

27. Wasilewski, MM.; Disch, PP.; McGill, JM.; Harris, HW.; O'Riordan, W.; Zeckel, ML.

Equivalence of shorter course therapy with oritavancin vs vancomycin/cephalexin in complicated skin/skin structure infections.. 41st Interscience Conference on Antimicrobial Agents and Chemotherapy.; Chicago, IL, USA. 2001; Paper 16-19

28. Patti GJ, Kim SJ, Yu TY, et al. Vancomycin and oritavancin have different modes of action in Enterococcus faecium. J Mol Biol. 2009; 5:1178-1191. [PubMed: 19576226]

29. Belley A, Neesham-Grenon E, McKay G, Arhin FF, Harris R, Beveridge T. Oritavancin kills stationary-phase and biofilm Staphylococcus aureus cells in vitro. Antimicrob Agents Chemother. 2009; 53:918-925. [PubMed: 19104027]

30. Lefort A, Saleh-Mghir A, Garry L, Carbon C, Fantin B. Activity of LY333328 combined with gentamicin in vitro and in rabbit experimental endocarditis due to vancomycin-susceptible or resistant Enterococcus faecalis. Antimicrob Agents Chemother. 2000; 44:3017-3021. [PubMed: 11036016]

31. Saleh-Mghir A, Lefort A, Petegnief Y, et al. Activity and diffusion of LY333328 in experimental endocarditis due to vancomycin-resistant Enterococcus faecalis. Antimicrob Agents Chemother. 1999; 43:115-120. [PubMed: 9869575]

32. Enoch DA, Bygott JM, Daly ML, Karas JA. Daptomycin. J Infect. 2007; 55:205-213. [PubMed: 17629567]

33. Silverman JA, Perlmutter NG, Shapiro HM. Correlation of daptomycin bactericidal activity and membrane depolarization in Staphylococcus aureus. Antimicrob Agents Chemother. 2003; 47:2538-2544. [PubMed: 12878516]

34. Akins RL, Rybak MJ. Bactericidal activities of two daptomycin regimens against clinical strains of glycopeptide intermediate-resistant Staphylococcus aureus, vancomycin-resistant Enterococcus faecium, and methicillin-resistant Staphylococcus aureus isolates in an in vitro pharmacodynamic model with simulated endocardial vegetations. Antimicrob Agents Chemother. 2001; 45:454-459. [PubMed: 11158740] 
35. Critchley IA, Blosser-Middleton RS, Jones ME, Thornsberry C, Sahm DF, Karlowsky JA. Baseline study to determine in vitro activities of daptomycin against gram-positive pathogens isolated in the United States in 2000-2001. Antimicrob Agents Chemother. 2003; 47:1689-1693. [PubMed: 12709341]

36. Pankey G, Ashcraft D, Patel N. In vitro synergy of daptomycin plus rifampin against Enterococcus faecium resistant to both linezolid and vancomycin. Antimicrob Agents Chemother. 2005; 49:5166-5168. [PubMed: 16304195]

37. Rice LB, Eliopoulos GM, Moellering RC Jr. In vitro synergism between daptomycin and fosfomycin against Enterococcus faecalis isolates with high-level gentamicin resistance. Antimicrob Agents Chemother. 1989; 33:470-473. [PubMed: 2543282]

38. Snydman DR, McDermott LA, Jacobus NV. Evaluation of in vitro interaction of daptomycin with gentamicin or beta-lactam antibiotics against Staphylococcus aureus and Enterococci by FIC index and timed-kill curves. J Chemother. 2005; 17:614-621. [PubMed: 16433191]

39. Arias CA, Torres HA, Singh KV, et al. Failure of daptomycin mono-therapy for endocarditis caused by an Enterococcus faecium strain with vancomycin-resistant and vancomycin-susceptible subpopulations and evidence of in vivo loss of the vanA gene cluster. Clin Infect Dis. 2007; 10:1343-1346. [PubMed: 17968832]

40. Stevens MP, Edmond MB. Endocarditis due to vancomycin-resistant enterococci: case report and review of the literature. Clin Infect Dis. 2005; 8:1134-1142. [PubMed: 16163631]

41. Jenkins I. Linezolid- and vancomycin-resistant Enterococcus faecium endocarditis: successful treatment with tigecycline and daptomycin. J Hosp Med. 2007; 2:343-344. [PubMed: 17935250]

42. Schutt AC, Bohm NM. Multidrug-resistant Enterococcus faecium endocarditis treated with combination tigecycline and high-dose daptomycin. Ann Pharmacother. 2009; 43:2108-2112. [PubMed: 19887592]

43. Jaspan HB, Brothers AW, Campbell AJ, McGuire JK, Browd SR, Manley TJ, et al. Multidrugresistant Enterococcus faecium meningitis in a toddler: characterization of the organism and successful treatment with intravecular daptomycin and tigecycline. Pediatr Infect Dis J. 2010

44. Toh SM, Xiong L, Arias CA, et al. Acquisition of a natural resistance gene renders a clinical strain of methicillin-resistant Staphylococcus aureus resistant to the synthetic antibiotic linezolid. Mol Microbiol. 2007; 64:1506-1514. [PubMed: 17555436]

45. Arias CA, Vallejo M, Reyes J, et al. Clinical and microbiological aspects of linezolid resistance mediated by the cfr gene encoding a 23S rRNA methyltransferase. J Clin Microbiol. 2008; 46:892-896. [PubMed: 18174304]

46. Birmingham MC, Rayner CR, Meagher AK, Flavin SM, Batts DH, Schentag JJ. Linezolid for the treatment of multidrug-resistant, gram-positive infections: experience from a compassionate-use program. Clin Infect Dis. 2003; 2:159-168. [PubMed: 12522747]

47. Baddour LM, Wilson WR, Bayer AS, et al. Committee on Rheumatic Fever, Endocarditis, and Kawasaki Disease; Council on Cardiovascular Disease in the Young; Councils on Clinical Cardiology; Stroke, and Cardiovascular Surgery and Anesthesia; American Heart Association; Infectious Diseases Society of America. Infective endocarditis: diagnosis, antimicrobial therapy, and management of complications: a statement for healthcare professionals from the Committee on Rheumatic Fever, Endocarditis, and Kawasaki Disease, Council on Cardiovascular Disease in the Young, and the Councils on Clinical Cardiology, Stroke, and Cardiovascular Surgery and Anesthesia, American Heart Association: endorsed by the Infectious Diseases Society of America. Circulation. 2005; 111:e394-e434. [PubMed: 15956145]

48. Falagas ME, Manta KG, Ntziora F, Vardakas KZ. Linezolid for the treatment of patients with endocarditis: a systematic review of the published evidence. J Antimicrob Chemother. 2006; 58:273-280. [PubMed: 16735427]

49. Zimmer SM, Caliendo AM, Thigpen MC, Somani J. Failure of linezolid treatment for enterococcal endocarditis. Clin Infect Dis. 2003; 3:e29-e30. [PubMed: 12884185]

50. Tsigrelis C, Singh KV, Coutinho TD, Murray BE, Baddour LM. Vancomycin-resistant Enterococcus faecalis endocarditis: linezolid failure and strain characterization of virulence factors. J Clin Microbiol. 2007; 45:631-635. [PubMed: 17182759] 
51. Berdal JE, Eskesen A. Short-term success, but long-term treatment failure with linezolid for enterococcal endocarditis. Scand J Infect Dis. 2008; 40:765-766. [PubMed: 18609208]

52. Mizell KN, Carter JE. Vancomycin-resistant Enterococcus faecium meningitis successfully treated with linezolid. South Med J. 2008; 101:569-570. [PubMed: 18458638]

53. Tsai TN, Wu CP, Peng MY, Giian CF, Lee SY, Lu JJ. Short course of linezolid treatment for vancomycin-resistant Enterococcus faecium meningitis. Int J Clin Pract. 2006; 60:740-741. [PubMed: 16805761]

54. Chant C, Rybak MJ. Quinupristin/dalfopristin (RP 59500): a new streptogramin antibiotic. Ann Pharmacother. 1995; 29:1022-1027. [PubMed: 8845540]

55. Aksoy DY, Unal S. New antimicrobial agents for the treatment of Gram-positive bacterial infections. Clin Microbiol Infect. 2008; 14:411-420. [PubMed: 18261129]

56. Cocito C, Di Giambattista M, Nyssen E, Vannuffel P. Inhibition of protein synthesis by streptogramins and related antibiotics. J Antimicrob Chemother. 1997; 39(suppl A):7-13. [PubMed: 9511056]

57. Bryson HM, Spencer CM. Quinupristin-dalfopristin. Drugs. 1996; 52:406-415. [PubMed: 8875130]

58. Singh KV, Murray BE. Differences in the Enterococcus faecalis lsa locus that influence susceptibility to quinupristin-dalfopristin and clindamycin. Antimicrob Agents Chemother. 2005; 49:32-39. [PubMed: 15616272]

59. Singh KV, Weinstock GM, Murray BE. An Enterococcus faecalis ABC homologue (Lsa) is required for the resistance of this species to clindamycin and quinupristin-dalfopristin. Antimicrob Agents Chemother. 2002; 46:1845-1850. [PubMed: 12019099]

60. Linden PK, Moellering RC Jr, Wood CA, et al. Treatment of vancomycin-resistant Enterococcus faecium infections with quinupristin/dalfopristin. Clin Infect Dis. 2001; 11:1816-1823. [PubMed: 11668430]

61. Matsumura S, Simor AE. Treatment of endocarditis due to vancomycin-resistant Enterococcus faecium with quinupristin/dalfopristin, doxycycline, and rifampin: a synergistic drug combination. Clin Infect Dis. 1998; 27:1554-1556. [PubMed: 9868693]

62. Bethea JA, Walko CM, Targos PA. Treatment of vancomycin-resistant enterococcus with quinupristin/dalfopristin and high-dose ampicillin. Ann Pharmacother. 2004; 38:989-991. [PubMed: 15100393]

63. Slover CM, Rodvold KA, Danziger LH. Tigecycline: a novel broad-spectrum antimicrobial. Ann Pharmacother. 2007; 41:965-972. [PubMed: 17519296]

64. Noskin GA. Tigecycline: a new glycylcycline for treatment of serious infections. Clin Infect Dis. 2005; 41(suppl 5):S303-S314. [PubMed: 16080069]

65. Werner G, Gfrorer S, Fleige C, Witte W, Klare I. Tigecycline-resistant Enterococcus faecalis strain isolated from a German intensive care unit patient. J Antimicrob Chemother. 2008; 61:1182-1183. [PubMed: 18285315]

66. Ellis-Grosse EJ, Babinchak T, Dartois N, Rose G, Loh E. The efficacy and safety of tigecycline in the treatment of skin and skin-structure infections: results of 2 double-blind phase 3 comparison studies with vancomycin-aztreonam. Clin Infect Dis. 2005; 5:S341-S353. [PubMed: 16080072]

67. Babinchak T, Ellis-Grosse E, Dartois N, Rose GM, Loh E. The efficacy and safety of tigecycline for the treatment of complicated intra-abdominal infections: analysis of pooled clinical trial data. Clin Infect Dis. 2005; 5:S354-S367. [PubMed: 16080073]

68. Entenza JM, Moreillon P. Tigecycline in combination with other antimicrobials: a review of in vitro, animal and case report studies. Int J Antimicrob Agents. 2009; 34(8):e1-e9. [PubMed: 19162449]

69. Peleg AY, Potoski BA, Rea R, et al. Acinetobacter baumannii bloodstream infection while receiving tigecycline: a cautionary report. J Antimicrob Chemother. 2007; 59:128-131. [PubMed: 17082201]

70. Reid KC, Cockerill IF, Patel R. Clinical and epidemiological features of Enterococcus casseliflavus/flavescens and Enterococcus gallinarum bacteremia: a report of 20 cases. Clin Infect Dis. 2001; 11:1540-1546. [PubMed: 11340524] 
71. Panesso D, Ospina S, Robledo J, et al. First characterization of a cluster of VanA-type glycopeptide-resistant Enterococcus faecium, Colombia. Emerg Infect Dis. 2002; 8:961-965. [PubMed: 12194774]

72. Norris AH, Reilly JP, Edelstein PH, Brennan PJ, Schuster MG. Chloramphenicol for the treatment of vancomycin-resistant enterococcal infections. Clin Infect Dis. 1995; 20:1137-1144. [PubMed: 7619989]

73. Lautenbach E, Schuster MG, Bilker WB, Brennan PJ. The role of chloramphenicol in the treatment of bloodstream infection due to vancomycin-resistant enterococcus. Clin Infect Dis. 1998; 27:1259-1265. [PubMed: 9827280]

74. Ricaurte JC, Boucher HW, Turett GS, Moellering RC, Labombardi VJ, Kislak JW. Chloramphenicol treatment for vancomycin-resistant Enterococcus faecium bacteremia. Clin Microbiol Infect. 2001; 7:17-21. [PubMed: 11284938]

75. Safdar A, Bryan CS, Stinson S, Saunders DE. Prosthetic valve endocarditis due to vancomycinresistant Enterococcus faecium: treatment with chloramphenicol plus minocycline. Clin Infect Dis. 2002; 34:E61-E63. [PubMed: 12015709]

76. Zinner SH, Gilbert D, Lubenko IY, Greer K, Firsov AA. Selection of linezolid-resistant Enterococcus faecium in an in vitro dynamic model: protective effect of doxycycline. $\mathrm{J}$ Antimicrob Chemother. 2008; 61:629-635. [PubMed: 18245198]

77. Van Nieuwkoop C, Visser LG, Groeneveld JH, Kuijper EJ. Chronic bacterial prostatitis and relapsing Enterococcus faecalis bacteraemia successfully treated with moxifloxacin. J Infect. 2008; 56:155-156. [PubMed: 18083235]

78. Rambaldi M, Ambrosone L, Migliaresi S, Rambaldi A. Combination of co-trimoxazole and ciprofloxacin as therapy of a patient with infective endocarditis caused by an enterococcus highly resistant to gentamicin. J Antimicrob Chemother. 1997; 40:737-738. [PubMed: 9421329]

79. Landman D, Quale JM, Mobarakai N, Zaman MM. Ampicillin plus ciprofloxacin therapy of experimental endocarditis caused by multidrug-resistant Enterococcus faecium. J Antimicrob Chemother. 1995; 36:253-258. [PubMed: 8537276]

80. Arias CA, Singh KV, Panesso D, Murray BE. Evaluation of ceftobiprole medocaril against Enterococcus faecalis in a mouse peritonitis model. J Antimicrob Chemother. 2007; 60:594-598. [PubMed: 17606481]

81. Arias CA, Singh KV, Panesso D, Murray BE. Time-kill and synergism studies of ceftobiprole against Enterococcus faecalis, including beta-lactamase-producing and vancomycin-resistant isolates. Antimicrob Agents Chemother. 2007; 51:2043-2047. [PubMed: 17438057]

82. Jacqueline C, Caillon J, Le Mabecque V, et al. In vivo activity of a novel anti-methicillin-resistant Staphylococcus aureus cephalosporin, ceftaro-line, against vancomycin-susceptible and -resistant Enterococcus faecalis strains in a rabbit endocarditis model: a comparative study with linezolid and vancomycin. Antimicrob Agents Chemother. 2009; 53:5300-5302. [PubMed: 19752276] 


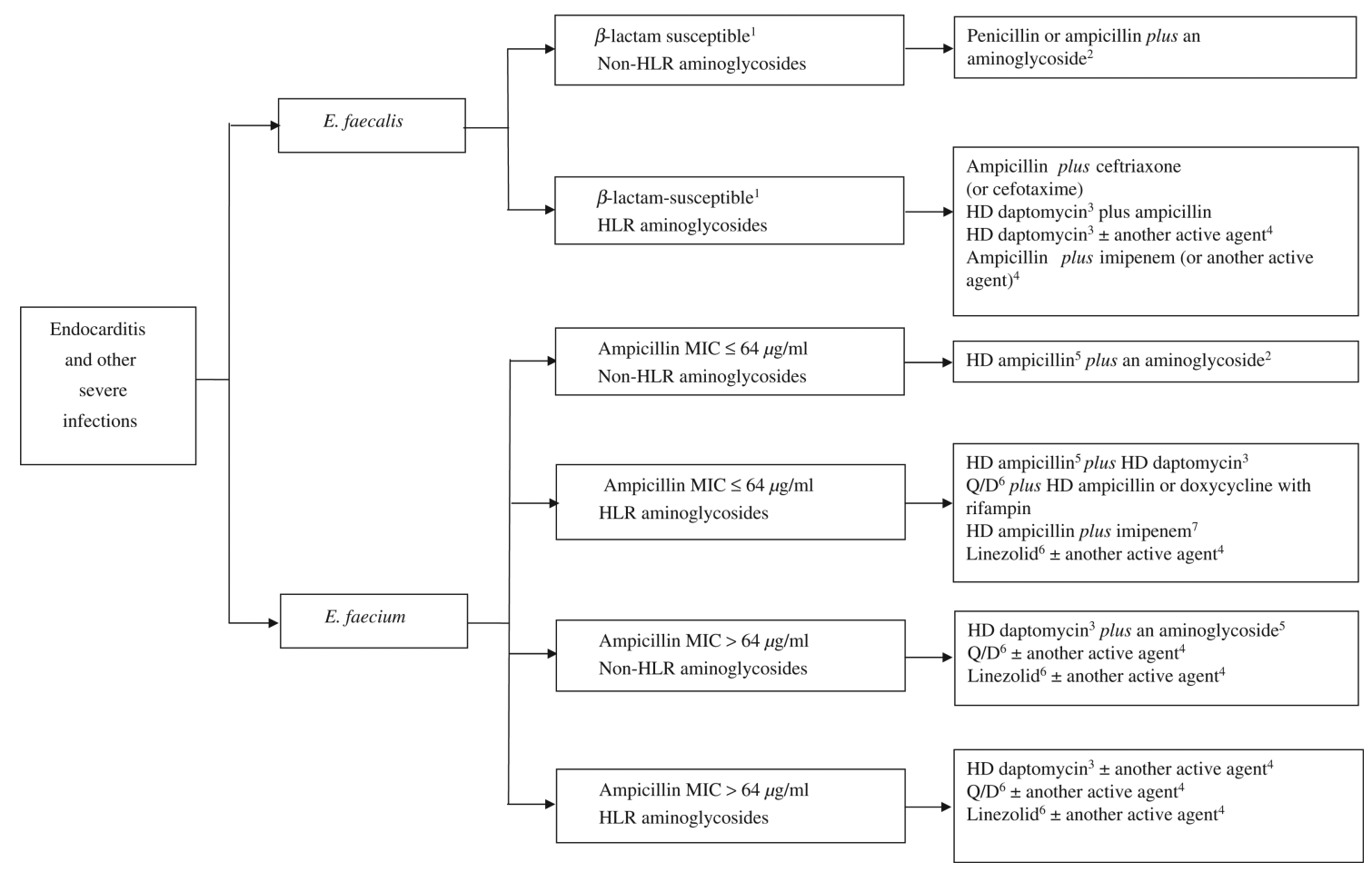

FIG. 1.

Suggested therapeutic alternatives in severe infections caused by vancomycin-resistant enterococcal infections. (1) In rare cases of $\beta$-lactamase-producing isolates, ampicillinsulbactam (12-24 g/day) is suggested. The use of a continuous infusion is recommended by some experts. (2) Gentamicin or streptomycin. (3) Consider doses of $8-12 \mathrm{mg} / \mathrm{kg}$ day. (4) Agents with potential activity include tigecycline [62,63], doxycycline with rifampin or a fluoroquinolone (if susceptible to each agent). (5) Doses to up to $30 \mathrm{~g} / \mathrm{day}$ could be considered. (6) Quinupristin-dalfopristin or linezolid are listed in the American Heart Association recommendations for the treatment of vancomycin and ampicillin-resistant Enterococcus faecium. Linezolid has been used with success in a few cases of meningitis as a result of vancomycin-resistant enterococci [61,74]. (7) if imipenem MIC $<32 \mathrm{mg} / \mathrm{L}$. HLR, high-level resistance; HD, high-dose. 
TABLE 1

Antibiotic options for the treatment of ampicillin- and vancomycin-resistant enterococcal infections

\begin{tabular}{|c|c|c|}
\hline Food and Drug Administration approved & Not approved but potential clinical use & Investigational \\
\hline $\begin{array}{l}\text { Linezolid } \\
\text { Quinupristin-dalfopristin }^{*}\end{array}$ & $\begin{array}{l}\text { Daptomycin } \\
\text { Tigecycline }^{\dagger} \\
\text { Nitrofurantoin }^{\xi} \\
\text { Fosfomycin }^{\xi} \\
\text { Doxycycline }^{\text {Il }} \text {, minocycline }{ }^{\mathscr{l}} \\
\text { Fluoroquinolones }^{\text {I }} \\
\text { Rifampin }^{\text {II }} \\
\text { Chloramphenicol }\end{array}$ & $\begin{array}{l}\text { Oritavancin } \\
\text { Ceftobiprole }{ }^{*} \\
\text { Ceftaroline }^{*}\end{array}$ \\
\hline
\end{tabular}

* Only Enterococcus faecium.

${ }^{\dagger}$ Not recommended as monotherapy.

${ }^{t}$ Only Enterococcus faecalis.

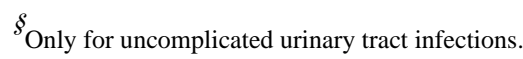

II Only if susceptible and as part of a combination regimen. 